\title{
59. Multiple Record Types
}

Many files do not contain records of only one type - but might contain records of various formats and lengths.

For example, a file might consist mainly of ordinary student records of the following layout:

$\begin{array}{ll}\text { name } & 20 \text { characters } \\ \text { address } & 60 \text { characters } \\ \text { course code } & 5 \text { characters }\end{array}$

However, the student records might be grouped within the file according to the course the student is following - with a record at the end of each group giving information about the course with a layout as follows:

$\begin{array}{ll}\text { course code } & 5 \text { characters } \\ \text { course name } & 20 \text { characters } \\ \text { course tutor } & 20 \text { characters } \\ \text { course description } & 40 \text { characters. }\end{array}$

It is possible to specify a number of different record types for one file as follows:

FD STUDENT-FILE.

01 STUDENT-RECORD.

$\begin{array}{lll}05 & \text { STUDENT-NAME PIC X }(20) . \\ 05 & \text { STUDENT-ADDRESS } & \text { PIC X }(60) . \\ 05 & \text { STUDENT-COURSE-CODE PIC X } & \text { P }\end{array}$

01 COURSE-RECORD.

$\begin{array}{lll}05 & \text { COURSE-CODE } & \text { PIC X(5). } \\ 05 & \text { COURSE-NAME } & \text { PIC X(20). } \\ 05 & \text { COURSE-TUTOR } & \text { PIC X(20). } \\ 05 & \text { COURSE-DESCRIPTION PIC X(20). }\end{array}$

It is important to note that the two record descriptions are simply two ways of describing the same area of Central Memory.

Although the record lengths are the same in this case, this does not have to be so.

Note also that this method of redescribing an area of store can only be used at the 01 Level in the File Section. A different method is used in the Working-Storage Section.

\section{Exercises}

1. Write a program which creates a file of student records (defined as above) interspersed with course records.

2. Write a program which reads and displays the file. 